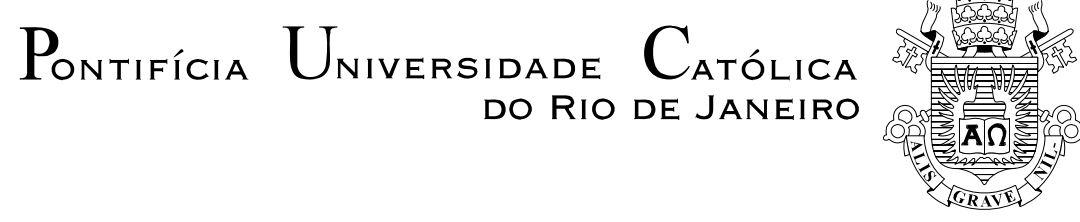

Beatriz Gang Mizrahi

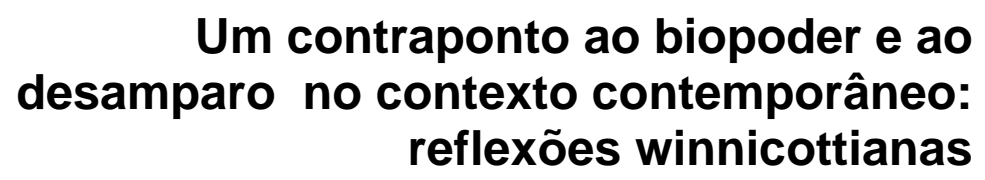

Tese de Doutorado

Tese apresentada ao Programa de Pós-graduação em Psicologia do Departamento de Psicologia da PUC-Rio como parte dos requisitos parciais para obtenção do título de Doutor em Psicologia Clínica.

Orientadora: Profa. Claudia Amorim Garcia

Rio de Janeiro

Fevereiro de 2008 


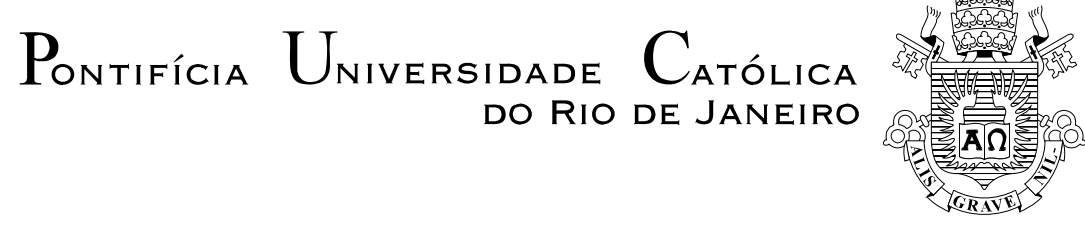

Beatriz Gang Mizrahi

\section{Um contraponto ao biopoder e ao desamparo no contexto contemporâneo: reflexões winnicottianas}

Tese apresentada como requisito parcial para obtenção do grau de Doutor pelo Programa de Pós-Graduação em Psicologia Clínica do Departamento de Psicologia do Centro de Teologia e Ciências Humanas da PUC-Rio. Aprovada pela Comissão Examinadora abaixo assinada.

Profa. Claudia Amorim Garcia

Orientadora

Departamento de Psicologia - PUC-Rio

Prof $^{\circ}$. Carlos Augusto Peixoto Junior Departamento de Psicologia - PUC-Rio

Profa. Esther Maria Magalhães Arantes

Departamento de Psicologia - PUC-Rio

Profo. André Martins Vilar de Carvalho IFCS - UFRJ

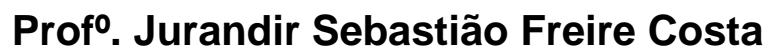

IMS - UERJ

Prof. Paulo Fernando Carneiro de Andrade Coordenador Setorial de Pós-Graduação e Pesquisa do Centro de Teologia e Ciências Humanas - PUC-Rio

Rio de Janeiro,

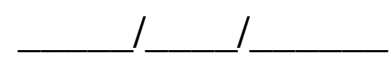


Todos os direitos reservados. É proibida a reprodução total ou parcial do trabalho sem autorização da autora, da orientadora e da universidade.

\section{Beatriz Gang Mizrahi}

Graduou-se em Psicologia na Pontifícia Universidade Católica do Rio de Janeiro em 1997. Psicóloga Clínica desde 1997. Concluiu especialização em Saúde Mental Infanto-Juvenil também na PUC-Rio em 1998 e em Psicologia Médica na UERJ (Universidade do Estado do Rio de Janeiro) em 2001. Obteve o grau de mestre em Psicologia pelo programa de PósGraduação em Psicologia da PUC-Rio em 2003.

Ficha Catalográfica

Mizrahi, Beatriz Gang

Um contraponto ao biopoder e ao desamparo no contexto contemporâneo: reflexões winnicottianas / Beatriz Gang Mizrahi ; orientadora: Claudia Amorim Garcia. - 2008.

163 f. : il. ; $30 \mathrm{~cm}$

Tese (Doutorado em Psicologia) - Pontifícia Universidade Católica do Rio de Janeiro, Rio de Janeiro, 2008.

Inclui bibliografia

1. Psicologia - Teses. 2. Biopoder. 3. Desamparo. 4. Vida espontânea. 5. Ambiente facilitador. 6. Resistência. 6. Cuidado de si. I. Garcia, Claudia Amorim. II. Pontifícia Universidade Católica do Rio de Janeiro. Departamento de Psicologia. III. Título. 


\section{Agradecimentos}

À Claudia Garcia, pela orientação firme e inteligente, capaz de oferecer um espaço generoso, onde puderam caber, construtivamente, também as nossas diferenças.

À FAPERJ que apoiou e tornou possível a realização deste trabalho.

À Edna Vilete, André Martins, Jurandir Freire Costa, Renato Barauna e aos demais colegas dos respectivos grupos de estudo. Vocês fizeram parte da experiência afetiva e teórica que sustentou a elaboração deste trabalho.

Às amigas Tatiana Katz, Elaine Decache, Valéria Rodrigues e Alzira Kuster pelas conversas proveitosas e importantíssimas onde minhas inquietações puderam encontrar acolhida.

A Carlos Augusto Peixoto pelas importantes sugestões na leitura do último Foucault.

A Esther Arantes pela rica troca de idéias.

A Carlos Plastino, meu analista, por me emprestar sua força e me ajudar a reconhecer a minha.

A meus pais, minha irmã e meus avós pelo suporte e inspiração. Nossa história foi marcada tanto por um dos efeitos mais devastadores do biopoder -o nazismoquanto pelos desvios esperançosos que permitiram a sobrevivência, a continuidade e o sentido da vida. Este trabalho fala dessas duas experiências que, em boa medida, me chegaram através de vocês.

A meus amores, Isaac e Juliana pelo enorme carinho e apoio ao longo desses anos de muito trabalho e pouco descanso. 


\section{Resumo}

Mizrahi, Beatriz Gang; Garcia, Claudia Amorim (Orientadora). Um contraponto ao biopoder e ao desamparo no contexto contemporâneo: reflexões winnicottianas. Rio de Janeiro, 2008. 163p. Tese de Doutorado - Departamento de Psicologia, Pontifícia Universidade Católica do Rio de Janeiro.

O presente estudo aborda o pensamento de Winnicott, buscando nele uma outra concepção da relação indivíduo/ sociedade distinta daquela que predomina hoje em nosso cenário social. A sua idéia de uma vitalidade espontânea e das condições necessárias para sua plena expressão contrasta com os dispositivos do biopoder descritos por Foucault que se apropriam da vida de modo a maximizar sua utilidade econômica. Ao mesmo tempo, a sua suposição de uma subjetividade que só pode emergir e diferenciar-se a partir da consistência do ambiente contrasta com a experiência de desamparo e vulnerabilidade descrita por Castel como característica do homem contemporâneo. Além disso, a noção winnicottiana de uma capacidade de preocupação com o outro que não depende de coerções e controles, mas de um ambiente cuidadoso internalizado, muito se aproxima das últimas análises de Foucault que tratam do cuidado de si antigo. Em tais análises, a ética greco-romana é entendida como expressão de liberdade, sendo retomada no presente sob a forma da amizade. Tanto Winnicott quanto Foucault sustentam a idéia de uma abertura potencial do indivíduo para o outro, mas é o primeiro autor quem, reconhecendo claramente as necessidades e tendências naturais da vida criativa, sem fechá-la em padrões normativos, nos permite criticar, por outro lado, o novo ideal de um sujeito totalmente aberto às demandas externas.

\section{Palavras-chave}

Biopoder, desamparo, vida espontânea, ambiente facilitador, resistência, cuidado de si. 


\section{Abstract}

Mizrahi, Beatriz Gang; Garcia, Claudia Amorim (Advisor). A counterpoint to biopower and helplessness in the contemporary context: winnicottian reflexions. Rio de Janeiro, 2008. 163p. PhD Thesis - Departamento de Psicologia, Pontifícia Universidade Católica do Rio de Janeiro.

The current study deals with Winnicott's thought, searching in it another conception of the individual/society relationship, different from the one that prevails today in the social scenario. His idea of a spontaneous vitality, and the necessary conditions for its full expression, opposes the biopower mechanisms described by Foucault that take life in a way to maximize its economic use. At the same time, his assumption of a subjectivity that can only emerge and differentiate itself supported by a consistent environment opposes the helplessness and vulnerability experience described by Castel as characteristic of the contemporaneous man. Besides that, Winnicott's notion of a capacity of concern with the other that does not depend on coercion and controls, but on an internalized careful environment, seems very close to Foucault latest analysis that deals with the concern of self in antiquity. In such analysis, the Greek-Roman ethics is understood as the expression of freedom, being recovered to the present in the form of friendship. Both Winninicott and Foucault support an idea of a potential openess of the individual to the other, but the former is the one who, clearly recognizing the needs and natural trends of creative life, without closing it in normative standards, allows us to criticize the new ideal of a subject completely open to the external demands.

\section{Keywords}

Biopower, helplessness, spontaneous life, good-enough environment, resistance, concern of self 


\section{Sumário}

Introdução

1. Biopoder e desamparo: de suas formas modernas a seus desdobramentos contemporâneos

1.1. Sobre os mecanismos de poder na era moderna 17

1.2. Sobre o biopoder na contemporaneidade 31

1.3. O problema do desamparo: questão central na modernidade que se intensifica na atualidade

1.4. Desafios do contemporâneo para a prática psicanalítica 53

2. O ambiente facilitador em Winnicott: uma alternativa para o desamparo e a regulação na experiência subjetiva

2.1. Uma psicanálise sem pulsão de morte $\quad 57$

2.2. O objeto subjetivo

2.3. Integração e personalização: processos fundamentais envolvendo a unidade psique-soma

2.4. A experiência transicional: um desvio em relação ao ideal de autonomia absoluta?

2.5. O uso de um objeto e a capacidade de se preocupar: a criação da alteridade como uma necessidade subjetiva

2.6. A moralidade como potencialidade natural

2.7. Um "estar só” que implica a presença de alguém

93

2.8. A clínica winnicottiana: uma forma de resistência na atualidade?

96

3. A subjetividade em Foucault: estabelecendo um diálogo possível com o pensamento winnicottiano

3.1. Identificando as principais questões trabalhadas pelo último Foucault 104

3.2. Os prazeres

3.3. Dietética e econômica

3.4. A erótica e a questão do verdadeiro amor

3.5. O cuidado de si

3.6. Uma outra relação sujeito e verdade: na moral antiga e no pensamento de Winnicott

3.7. A amizade como espaço transicional: pensando as formas de resistência política na atualidade

Conclusão

Referências bibliográficas 